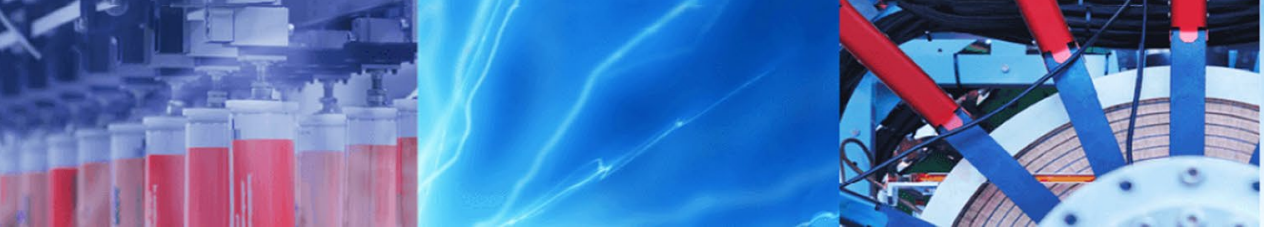

Research Article

\title{
Effect of the addition of pie-shaped ribs and parallelogram ribs in micro-channels on thermal performance using diamond-water nanofluid
}

\author{
Kamel Chadi $^{1} \cdot$ Nourredine Belghar $^{1} \cdot$ Belhi Guerira $^{2} \cdot$ Mohammed Lachi $^{3} \cdot$ Mourad Chikhi $^{4}$
}

Received: 8 July 2020 / Accepted: 28 January 2021 / Published online: 12 February 2021

(c) The Author(s) $2021 \quad$ OPEN

\begin{abstract}
In this paper, we numerically study the influence of the addition of parallelogram ribs and pie-shaped ribs in microchannels on thermal exchange in three dimensions. We design four different silicon micro-channel heat sinks; the first and second cases without ribs, the third case with added pie-shaped ribs, and a fourth case containing parallelogram ribs. The main purpose of this research is to determine the best micro-channel heat sink in which the heat dissipation is sufficient to improve the heat exchange performance of the micro-channel, as well as to improve the cooling of the electronic components. A constant heat flux is applied to the bottom wall of the four micro-channels, and we use liquid diamond-water with a volume concentration of $5 \%$ diamond nanoparticles as a coolant, with a Reynolds number chosen between 200 and 600 . The numerical results show that the Nusselt number $(\mathrm{Nu})$ of the micro-channel that contains the parallelogram ribs is higher than that for the other cases, and it also yiels lower temperature values on the bottom wall of the substrate compared to the micro-channel containing pie ribs. When increasing the flow velocity, the thermal resistance of the micro-channel decreases in all cases, and we then find the largest value of the friction factor in the fourth case (with parallelogram ribs).
\end{abstract}

Keywords Thermal exchange · Parallelogram ribs · Pie ribs · Micro-channel · Numerical simulation · Nanofluid

\section{Introduction}

The field of electronics has witnessed remarkable developments recently. The tremendous proliferation of electronic devices made possible by the miniaturization of electronic components and increased operating performance has led to high-temperature problems. The temperature can be improved by improving the heat exchange in a particular engineering scheme through several methods, including adjusting the geometry [1], adding fins [2], and the use of surface roughness [3], as well as by changing the physical properties of the fluid used in the cooling process [4] and disrupting the flow to create turbulence, which contributes to an increase in heat exchange [5]. In addition, researchers have suggested using several techniques to improve heat exchange. For example, Safaei et al. [6] numerically investigated heat transfer by forced convection of multi-walled water/liquid carbon nanotubes (FMWCNT) in a 2D micro-channel. They used the numerical method of finite volume and the Semi-Implicit Method for Pressure-Linked Equations (SIMPLE) algorithm. They also studied the impact of several values of shear force, volume

\footnotetext{
$\triangle$ Kamel Chadi, chadikamel_dz@yahoo.fr; Nourredine Belghar, n.belghar@univ-biskra.dz; Belhi Guerira, b.guerira@univ-biskra.dz; Mohammed Lachi, m.lachi@univ-reims.fr; Mourad Chikhi, chikhi.mrd@gmail.com| 'Laboratory of Materials and Energy Engineering, University of Mohamed Khider Biskra, Biskra, Algeria. ${ }^{2}$ Laboratory of Mechanical Engineering, University of Mohamed Khider Biskra, Biskra, Algeria. ${ }^{3}$ Laboratoire ITheMM Faculté des Sciences Exact. Et Nat. - Moulin de La Housse, BP. 1039, 51687 Reims, France. ${ }^{4}$ UDES, Route Nationale $N^{\circ} 11$, BP 386, 42415 Bou-Ismail, Wilaya de Tipaza, Algérie.
} 
fraction of solid nanoparticles, periodic thermal flux, and slip coefficient on the flow and temperature fields, as well as the rate of thermal transfer for Reynolds numbers (Re) from 1 to 100 and the weight percentage of solid nanoparticles between 0 and $25 \%$. Their results showed perfect agreement with the experimental and numerical studies of other researchers. They also found that the local Nusselt number along the micro-channel changes periodically and increases with the increase in the Reynolds number, and an increase in the weight percentage of nanoparticles leads to an increase in the Nusselt number.

Ding et al. [7] experimentally and numerically investigated heat exchange and friction characteristics with rectangular, semicircular, and triangular ribs on the sidewalls of micro-fluidic channels by a surface micromachining microelectromechanical system to improve the heat transfer rate of the microfluidic heat sink. They found that the use of micro-ribs provided a better heat exchange rate. They further observed that the heat transfer and friction characteristics of the micro-channels were strongly influenced by the rib form, with the triangular ribbed microchannel possessing the largest Nusselt number and friction factor among the three rib shapes.

Goodarzi et al. [8] numerically studied heat transfer with the mixed convection of various water and copper nanofluids inside a microtube with a $90^{\circ}$ curvature angle, using the finite volume method. They chose a Reynolds number equal to 10 and nanoparticle volume fractions from 0 to $6 \%$. Their results showed that this model was superior to those in previous numerical and experimental studies. They also reported that the heat transfer and the behavior of the hydraulics of the nanofluids in curved geometric shapes varied to a certain extent with other geometric shapes and flat surfaces due to the simultaneous presence of buoyancy and centrifugal forces.

Similarly, Safaei et al. [9] examined the mixed convection heat transfer of various water and copper nanofluids through an inclined ribbed micro-channel using the finite volume method for a Reynolds number of 50 , inclination angles ranging from $0^{\circ}$ to $90^{\circ}$, and nanoparticle size fractions from 0.0 to 0.04 . They studied the effect of nanoparticle volume concentration, inclination angle, buoyancy and shear forces, and rib shape on the hydraulics and thermal behavior of nanofluid flow. They concluded that increasing the angle of inclination of the micro-channel or the volume fraction of solid particles enhanced the rate of heat transfer, and that the presence of ribs across the flow path led to a velocity gradient and increased heat transfer between the walls of the micro-channel and the nanofluid. Among the cases they examined, they found that a vertical micro-channel yielded the maximum heat transfer.

Akbari et al. [10] studied laminar flow $(\mathrm{Re}=10$ and 100$)$ for the convection heat transfer of water- $\mathrm{Al}_{2} \mathrm{O}_{3}$ nanofluids with volume fractions of 0.00 to 0.04 inside a two-dimensional rectangular micro-channel with ribs. They studied the effect of the height, position of the rib, concentration of the nanoparticles, and the Reynolds number on the thermal and hydraulic behavior of the nanofluid flow. They reported that the normal internal ribs, or turbulators, significantly enhanced the convective heat transfer within a micro-channel. They likewise affirmed that changing the volume concentration and the rib height resulted in considerable changes in dimensionless velocity and temperature along the centerline of the flow, through the ribbed areas.

Behnampour et al. [11] studied laminar flow with respect to the impact of trapezoidal, triangular, and rectangular ribs on the heat exchange of $\mathrm{H}_{2} \mathrm{O}-\mathrm{Ag}$ nanofluid in a ribbed triangular channel with nanoparticle volume fractions of 0,2 , and $4 \%$. They reported that an increase in volume concentration of solid nanoparticles led to an increase in convection heat exchange of the cooling nanofluid, whereas increasing the Nusselt number resulted in a loss of pressure and friction coefficient, with the lowest heat transfer values for the rectangular rib.

Goodarzi et al. [12] studied the effect of using aluminum oxide nanoparticles in a non-Newtonian liquid from an aqueous solution of carboxymethyl cellulose in microtubes, where they assumed that the nanofluids were homogeneous and assumed a constant microtube wall temperature. Their results indicated that adding nanoparticles to the base fluid and increasing the microtube slip coefficient might improve the heat exchange rate in the microtube.

Sharad and Sagar [13] studied heat exchange enhancement in a plain micro-channel heat sink (MCHS). Six different types of offset ribs were added on the micro-channel sidewall, including rectangular, backward triangular, forward triangular, and a mix of forward isosceles and semicircular. A Reynolds number of between 200 and 800 was used. They found that mixing of forward and backward offset ribs in the MCHS provided better results than other types of channels. They also concluded that with an increase in the Reynolds number, the Nusselt number increased and the friction factor decreased for the selected MCHS.

Jadhav et al. [14] performed a numerical investigation of the effect of different pin fin shapes (ellipse, circle, square, and hexagon) on a micro-channel. They concluded that for fin pins at larger height and at high coolant inlet flow velocities, the Nusselt number increased. They found that the square pin fins were the best among the studied pin fin shapes in terms of thermal performance.

Rezazadeh et al. [15] studied the effect of attack angles, height, Reynolds number, and rib arrangement on the performance of a mini-channel. They concluded that heat 
transfer efficiency increased with an increase in rib height and Reynolds number, and that arrangements with attack angles of $60^{\circ}$ had better heat transfer performance. They also concluded that mini-channels with both rectangular and trapezoidal ribs produced better results for heat transfer and fluid performance than a mini-channel with rectangular ribs.

In another study, Bagherzadeh et al. [16] investigated laminar flow using Reynolds numbers of 1,10 , and 50, and water/fluid nanofluid $\mathrm{Al}_{2} \mathrm{O}_{3}$ with volumes of $0,0.3$, and 0.06 inside a small rectangular channel in order to enhance heat transfer under a homogeneous magnetic field with forces of $\mathrm{H}_{a}=0,20$, and 40 . The results showed that in the case of a creep motion state, the narrow cross section caused by fluid flow could not be observed and that the increase in axial velocity was only due to the presence of an additional size of the micro-channel.

Goodarzi et al. [17] modeled the flow of nanofluids in micro-channel heat sinks with different cross sections (circular, trapezoid, and square) of the same length and hydraulic diameter. The authors used graphene-silver/ water nanoparticles in concentrations from 0 to 0.1 vol.\%, and Reynolds numbers between 200 and 1000 . They also examined the heat transfer in the laminar flow and concluded in the latter that a higher temperature led to a smaller Nusselt number, pressure drop, and pumping force, and an increase in the volume concentration of the nanoparticles led to an expected increase in heat transfer. They further concluded that an increase in the Reynolds number led to a decrease in the pressure and pumping force and an increase in the Nusselt number, while the friction factor decreased.

Bahiraei et al. [18] evaluated the thermo-hydraulic properties of hybrid nanofluids containing nanoparticles of graphene and silver in a heat sink with nanofluids equipped with ribs and secondary channels. Their results showed that the use of nanofluids, ribs, and secondary channels in the micro-channel greatly improved the performance of the heat sink. They also confirmed that increasing the volume concentration and Reynolds number helped to decrease the temperature and improved the average heat transfer coefficient with convection.

Among studies of interest in the field of electronic cooling and improved heat exchange, Gheynani et al. [19] studied the impacts of nanoparticle diameter and concentration on the speed and temperature fields of turbulent nonNewtonian carboxymethyl cellulose (CMC)/CuO nanofluid in a 3D microtube. They modeled $\mathrm{CMC} / \mathrm{CuO}$ using a nonNewtonian model of a power law. Using Reynolds numbers of 2500,4500 , and 6000 , the authors found that by reducing the nanoparticle diameter from 50 to $25 \mathrm{~nm}$, while keeping the Reynolds number constant, a $0.34 \%$ increase in the heat transfer coefficient with convection was observed. When using a Reynolds number of 2500 with an increase in the concentration of nanoparticles with a diameter of $25 \mathrm{~nm}$ from 0.5 to $1 \%$, the average Nusselt number increased by almost $0.1 \%$. These results can help researchers in the field of electronic device cooling.

Among recent studies on improved heat transfer, Wang et al. [20] numerically studied the heat transfer and flow characteristics of a micro-channel heat sink with truncated ribs (TRs) on the sidewall for a Reynolds number between 100 and 1000. They investigated the effects of rib geometry on hydrothermal performance and found that the TR improved the overall thermal performance by reducing the pressure drop penalty, with no loss of heat transfer.

The main objective of the present study was to find suitable micro-channel geometry to improve the cooling of the electronic components and enhance thermal performance of the micro-channel, as we changed the form of the micro-channel geometry by adding wavy walls located along two-thirds of the length $(2 / 3 \mathrm{~L})$ of the micro-channel from the micro-channel outlet. The wavy walls of the micro-channel helped dissipate heat, similar to rectangular micro-channels that have been researched extensively.

To further improve the thermal performance, we used diamond aqueous nanofluid at a concentration of 0.05 and studied two other cases in which we used parallelogram ribs and pie ribs in order to determine which of the two would contribute to better heat dissipation and also improve the thermal performance of the micro-channel.

This work is organized into seven sections: The first section presents the introduction. The second section discusses the physical characteristics of the nanofluid used in the simulation process. In the third section, the geometries of the micro-channels selected for the test are represented and dimensioned using Ansys Fluent software. The fourth section presents the governing equations and corresponding boundary conditions, along with the mathematical relations used in this study, including the calculation of the average heat transfer coefficient $\left(h_{\text {ave }}\right)$, the hydraulic diameter $\left(D_{h}\right)$, the thermal resistance, and the average fanning friction factor $(f)$. The results are validated in the fifth section, and in the sixth section, the independence of the solution is tested using simulation, and the simulation results are presented in the form of contours and curves with interpretations. Finally, a conclusion summarizing the main results is given at the end of this article, with some recommendations for future studies.

\section{Thermophysical properties of the nanofluid}

The formulas for the calculation of the thermophysical properties of the nanofluids are considered in this section. 
The effective thermal conductivity of the nanofluid $\left(k_{\mathrm{nf}}\right)$ is empirically correlated by [21] as follows:

$k_{\mathrm{nf}}=\left[1+1.4 \operatorname{Re}^{0.4} \operatorname{Pr}^{0.66}\left(\frac{T_{\mathrm{nf}}}{T_{f}}\right)^{10}\left(\frac{k_{s}}{k_{f}}\right)^{0.03} \varphi^{0.66}\right] k_{f}$

where $k_{s^{\prime}} k_{f \prime}$ and $\varphi$ are the thermal conductivity of the solid, the thermal conductivity of fluid (water), and volume fraction, respectively.

The dynamic viscosity $\left(\mu_{\mathrm{nf}}\right)$ is approximated by the Brinkman model [22] as follows:

$\mu_{\mathrm{nf}}=\frac{\mu_{f}}{(1-\varphi)^{2,5}}$

where $\mu_{f}$ is the dynamic viscosity of coolant.

The density of the nanofluid $\left(\rho_{\mathrm{nf}}\right)$ is given as [23]:

$\left.\rho_{\mathrm{nf}}=(1-\varphi) \rho_{f}+\varphi \rho_{s}\right)$

where $\rho_{f}$ and $\rho_{s}$ are the density of the fluid and the solid, respectively.

The heat capacitance of the nanofluid $\left(C p_{n f}\right)$ is expressed as given by Khanafer et al. [23]:

$\left(\rho C_{P}\right)_{\mathrm{nf}}=(1-\varphi)\left(\rho C_{p}\right)_{f}+\varphi\left(\rho C_{P}\right)_{s}$

where $C_{p}$ is the specific heat of the fluid.

The thermal expansion coefficient of the nanofluid $\left(\beta_{\mathrm{nf}}\right)$ is expressed as given by Khanafer et al. [23]:

$\rho_{\mathrm{nf}} \beta_{\mathrm{nf}}=(1-\varphi) \rho_{f} \beta_{f}+\varphi \rho_{s} \beta_{s}$

where $\beta_{f}$ and $\beta_{s}$ are the thermal expansion coefficients of the fluid and the solid, respectively.

The thermophysical properties of the pure fluid and nanoparticles are presented in Table 1.

\section{Geometric system}

The geometries of the system are represented using the commercial Ansys Fluent software, based on the microchannel heat sinks. The micro-channel with a rectangular cross section consists of 20 micro-channels. Each micro-channel has a length $L$, a width $W_{c}$, and a height $H_{c}$. The unvaried total area being cooled (bottom area) is $10 \mathrm{~mm} \times 5 \mathrm{~mm}$. Due to the symmetry, we have considered only the single micro-channel in each case, as presented in Fig. 1a. Heat was supplied to the silicon substrate through the bottom surface where the electronic components are joined.

The thermal flux produced by the electronic component $Q=100 \mathrm{~W} / \mathrm{cm}^{2}$, and heat insulation on all outside faces of the heat sinks are considered.
Table 1 Thermophysical properties of water and nanoparticles at $T=300 \mathrm{~K}$

\begin{tabular}{lll}
\hline & $\begin{array}{l}\text { Water (base } \\
\text { fluid) [24] }\end{array}$ & $\begin{array}{l}\text { Diamond } \\
\text { nanoparticles } \\
{[25]}\end{array}$ \\
\hline Density $\left(\mathrm{kg} / \mathrm{m}^{3}\right)$ & 998.2 & 3500 \\
Specific heat $\left(\mathrm{Jkg}^{-1} \mathrm{~K}^{-1}\right)$ & 4182 & 509 \\
Thermal conductivity $\left(\mathrm{Wm}^{-1} \mathrm{~K}^{-1}\right)$ & 0.613 & 2300 \\
Dynamic viscosity $(\mathrm{kg} / \mathrm{ms})$ & 0.001003 & - \\
\hline
\end{tabular}

The dimensions of the studied cases are given in Table 2.

\section{Mathematical formulation}

In this study, we assumed that the flow is stationary. The diamond-water nanofluid considered is supposed to be Newtonian, incompressible ( $\rho=$ constant), and laminar. The thermophysical properties of diamond $-\mathrm{H}_{2} \mathrm{O}$ nanofluid are constant. The heat exchange by radiation is considered negligible.

The boundary conditions at the inlet are written as follows:

$u=v=0$

$w=w_{\text {inlet }}=$ constan $t, T=T_{\text {inlet }}=$ constan $t$

where $u, v$, and $w$ are the velocity components in the $x$-axis, $y$-axis, and $z$-axis, respectively, and $T$ is the temperature.

At the outlet, we can write: the gauge pressure is zero.

At the walls of the micro-channel, we can write:

$u=v=w=0, T=T_{\text {wall }}$

At the fluid-solid interface, the continuity of the heat flux at the interface between the solid and the fluid is implemented using the following formula:

$k_{s}{\frac{\partial T}{\partial n_{\text {wall }}}}^{=} k_{f} \frac{\partial T}{\partial n_{\text {wall }}}$

where $n$ is the outer normal coordinate at the interface between the wall and fluid.

No-slip boundary conditions are applied to all cases of micro-channel walls. A constant heat flux is applied to the bottom wall. The top wall of the micro-channels is assumed to be adiabatic.

Governing equations are governed by the continuity equation, momentum equation, energy conservation equation, and the equation of the solid [26].

The continuity equation is written as follows: 
(a)

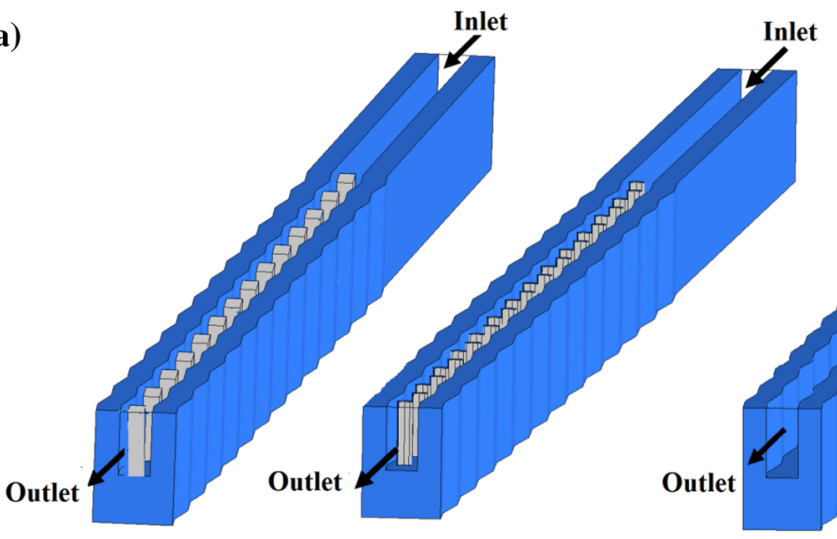

(d) case 4 (c) case 3 (b) case 2
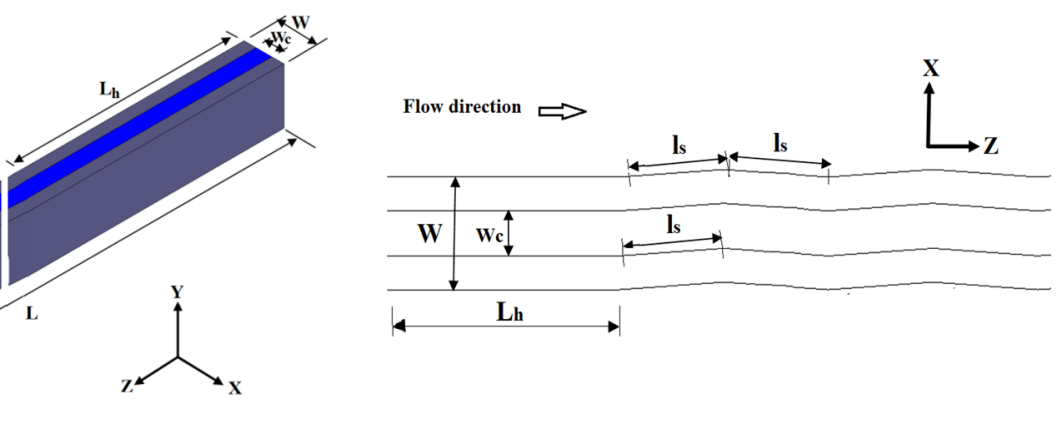

(d)

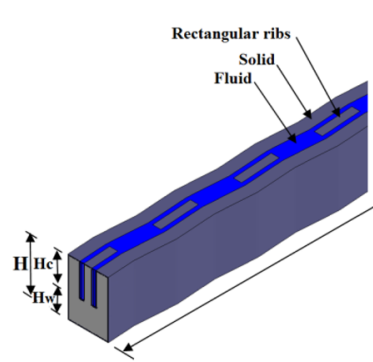

Fig. 1 Studied cases of the micro-channel heat sinks (MCHS). a Case 1: Single rectangular micro-channel without ribs. b Case 2: A quarter of the length $(L)$ of the channel is rectangular, and the remaining length $(L)$ is wavy. c Case 3 : The same as the second case,
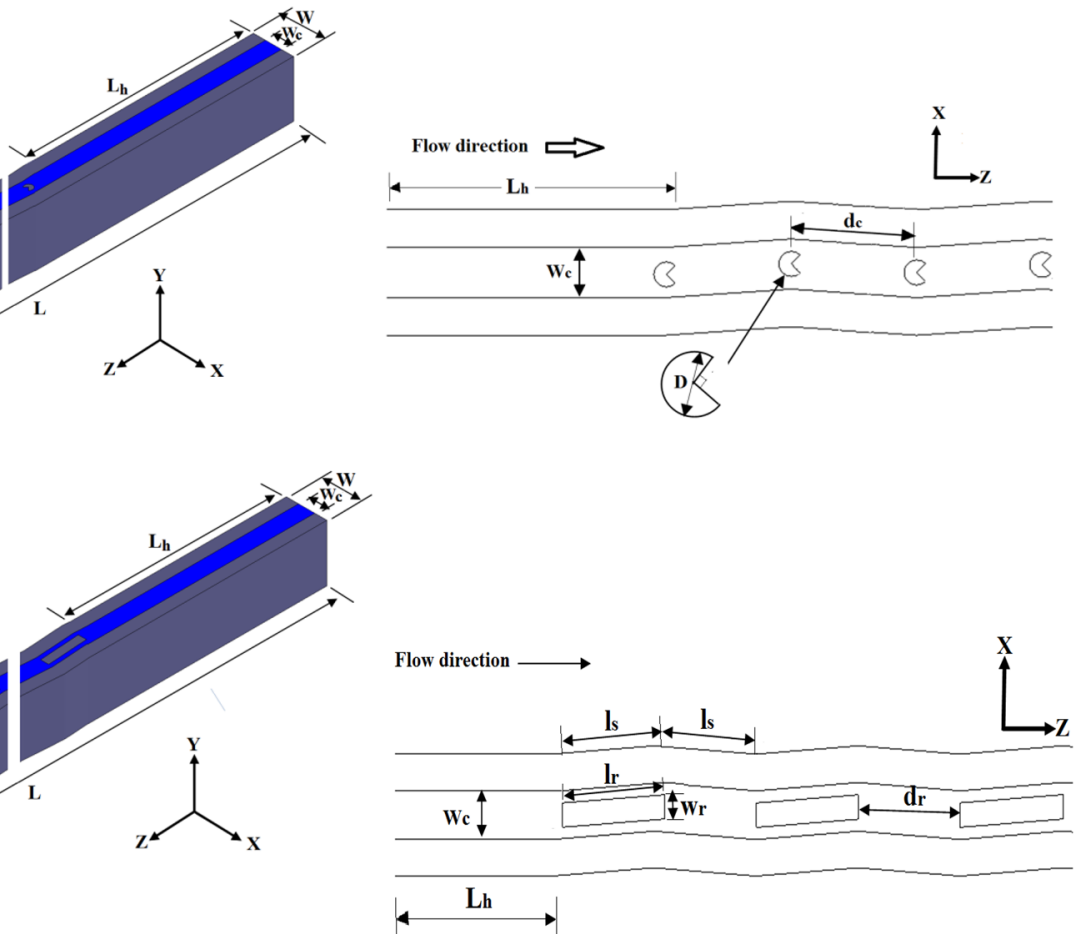

with the addition of pie-shaped ribs located at $z=6.67 \mathrm{~mm}$ from the micro-channel exit. d Case 4: The same as the second case, with the addition of parallelogram ribs located at $z=6.67 \mathrm{~mm}$ from the micro-channel exit 
Table 2 Geometric dimensions of the studied cases

\begin{tabular}{lllll}
\hline & Case 1 & Case 2 & Case 3 & Case 4 \\
\hline L (mm) (base fluid) & 10 & 10 & 10 & 10 \\
H (mm) & 0.35 & 0.35 & 0.35 & 0.35 \\
W (mm) & 0.25 & 0.25 & 0.25 & 0.25 \\
Hc (mm) & 0.20 & 0.20 & 0.20 & 0.20 \\
Wc $(\mathrm{mm})$ & 0.10 & 0.10 & 0.10 & 0.10 \\
Is $(\mathrm{mm})$ & - & 0.25 & 0.25 & 0.25 \\
Ir $(\mathrm{mm})$ & - & - & - & 0.25 \\
Lh $(\mathrm{mm})$ & 3.33 & 3.33 & 3.33 & 3.33 \\
Hw $(\mathrm{mm})$ & 0.15 & 0.15 & 0.15 & 0.15 \\
Wr $(\mathrm{mm})$ & - & - & - & 0.05 \\
$\mathrm{dr}(\mathrm{mm})$ & - & - & - & 0.25 \\
$\mathrm{dc}(\mathrm{mm})$ & - & - & 0.25 & - \\
D $(\mathrm{mm})$ & - & - & 0.05 & - \\
\hline
\end{tabular}

$\frac{\partial u}{\partial x}+\frac{\partial v}{\partial y}+\frac{\partial w}{\partial z}=0$

The momentum equations along the $x$-axis, $y$-axis, and $z$-axis are written as follows:

$x$-axis:

$\left\{\begin{array}{l}u \frac{\partial u}{\partial x}+v \frac{\partial u}{\partial y}+w \frac{\partial u}{\partial z} \\ =\frac{1}{\rho_{n f}}\left[-\frac{\partial P}{\partial x}+\mu_{n f}\left(\frac{\partial^{2} u}{\partial x^{2}}+\frac{\partial^{2} u}{\partial y^{2}}+\frac{\partial^{2} u}{\partial z^{2}}\right)\right]\end{array}\right\}$

$y$-axis:

$\left\{\begin{array}{l}u \frac{\partial v}{\partial x}+v \frac{\partial v}{\partial y}+w \frac{\partial v}{\partial z} \\ =\frac{1}{\rho_{n f}}\left[-\frac{\partial P}{\partial y}+\mu_{n f}\left(\frac{\partial^{2} v}{\partial x^{2}}+\frac{\partial^{2} v}{\partial y^{2}}+\frac{\partial^{2} v}{\partial z^{2}}\right)\right]\end{array}\right\}$

z-axis:

$\left\{\begin{array}{l}u \frac{\partial w}{\partial x}+v \frac{\partial w}{\partial y}+w \frac{\partial w}{\partial z} \\ =\frac{1}{\rho_{n f}}\left[-\frac{\partial P}{\partial z}+\mu_{n f}\left(\frac{\partial^{2} w}{\partial x^{2}}+\frac{\partial^{2} w}{\partial y^{2}}+\frac{\partial^{2} w}{\partial z^{2}}\right)\right]\end{array}\right\}$

where $\rho_{\mathrm{nf}}, \mu_{\mathrm{nf}}$ and $P$ are the density, dynamic viscosity, and the pressure of the nanofluid, respectively.

The energy equation is written as follows:

$u \frac{\partial T}{\partial x}+v \frac{\partial T}{\partial y}+w \frac{\partial T}{\partial z}=\alpha_{n f}\left(\frac{\partial^{2} T}{\partial x^{2}}+\frac{\partial^{2} T}{\partial y^{2}}+\frac{\partial^{2} T}{\partial z^{2}}\right)$

where $T$ is the temperature and $\alpha_{\mathrm{nf}}$ is the thermal diffusivity of the nanofluid.

The heat conduction through the solid wall is expressed as follows: $\frac{\partial^{2} T_{S}}{\partial x^{2}}+\frac{\partial^{2} T_{S}}{\partial y^{2}}+\frac{\partial^{2} T_{S}}{\partial z^{2}}=0$

The hydraulic diameter $\left(D_{h}\right)$ is defined as the ratio of the cross-sectional area over the wetted parameter, and it is calculated using (16) [24]:

$D_{h}=\frac{4 \cdot A_{c}}{P_{c}}$

where $A c$ and $P c$ are the cross-sectional area of the microchannel and wetted perimeter, respectively.

The average heat transfer coefficient $\left(h_{\mathrm{av}}\right)$ of the micro-channels is determined using (17) $[26,27]$ :

$h_{\mathrm{av}}=\frac{Q}{N A_{w}\left(T_{w}-T_{m}\right)}$

$N u=\frac{h_{\mathrm{av}} D_{h}}{k_{\mathrm{nf}}}$

where $A_{w}, T_{w}, N, k_{\mathrm{nf}}, T_{m}$, and $Q$ are the convection heat transfer area, average temperature of the wall, number of micro-channels, fluid thermal conductivity, average temperature of the fluid, and heat flux dissipated in the chip, respectively.

The Reynolds number is defined as [27]

$\operatorname{Re}=\frac{\rho_{\mathrm{nf}} \cdot W \cdot D_{h}}{\mu_{\mathrm{nf}}}$

The average fanning friction factor $(f)$ is calculated by the following equation [28]:

$f=\frac{\left(P_{\text {in }}-P_{\text {out }}\right) D_{h}}{2 \rho_{\text {nf }} \cdot W^{2} \cdot L}$

where $\left(p_{\text {in }}-p_{\text {out }}\right)$ and $L$ are the difference between the inlet pressure and outlet pressure and the length of the microchannel, respectively.

The thermal resistance of the heat sink is calculated by [1]:

$R_{\mathrm{th}}=\frac{T_{\max }-T_{\text {in }}}{Q}$

where $T_{\max }$ and $T_{\text {in }}$ are the maximum temperature on the bottom wall and the fluid inlet temperature, respectively.

\section{Validation of the results}

To validate our numerical results, we chose to compare the results obtained with those of Chai et al. [29]. 


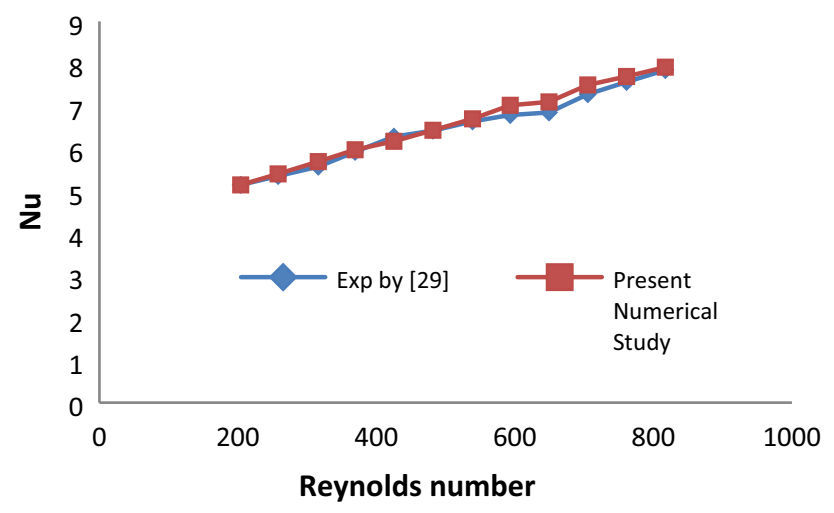

Fig. 2 Comparison of numerical results for Nusselt number vs. Re with results of Ref. [29] for the smooth micro-channel

Figure 2 presents the validation of our simulation for the variation in the Nusselt number versus several values of the inlet Reynolds number with the experimental results of Chai et al. [29] for the smooth micro-channel.

From these results, it is clear that the Nusselt number increases with the inlet Reynolds number between 200 and 800 . These results show perfect agreement with the results of Chai et al.

\section{Results and interpretation}

In this work we have chosen a hexahedron mesh (structured mesh) in three directions $(x, y$, and $z)$. After the simulation calculations converged, we tested mesh independence. Figure 3 shows the meshing view in three dimensions (3D), with 972,972 nodes ( 27 nodes in direction $x, 36$ nodes in direction $y$, and 1001 nodes in direction $z)$.

Figure 4 shows the number of nodes used for analysis of the micro-channel in case 1 with the resulting Nusselt number. According to this figure, we can conclude that the solution is independent of the mesh.

Tables 3, 4, and 5 show the aspect ratio, skewness, and orthogonal quality for the four cases, respectively.

The governing equations were solved using Ansys Fluent software, which relies upon the finite volume method (FVM). The FVM relies upon on the spatial integration of conservation equations on finite control volumes, which transforms the governing equations into algebraic equations, where they are solved. The SIMPLE algorithm was utilized to execute pressure-velocity coupling.

The under-relaxation factors utilized in this study are 0.7 and 0.3 for momentum conservation and for pressure, respectively. The residuals for the continuity equation and velocity components were in the order of $10^{-5}$, and

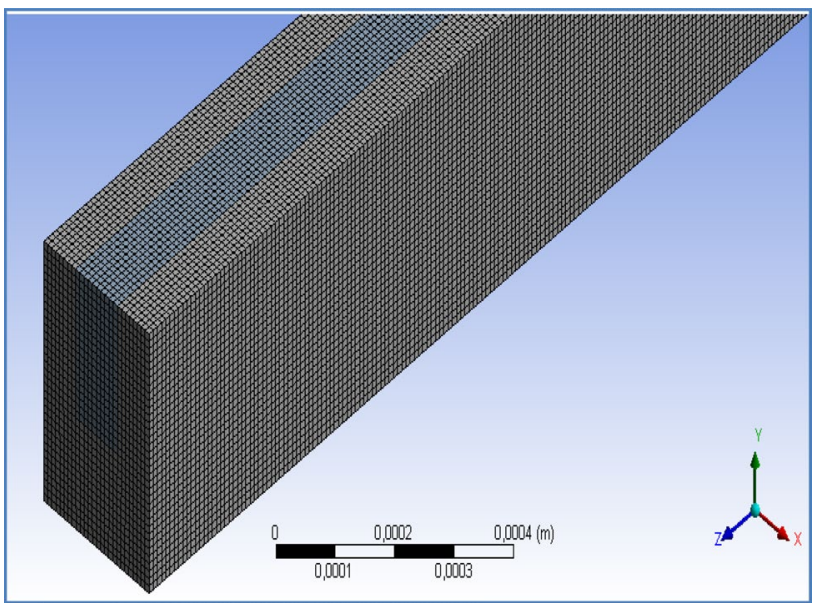

Fig. 3 Meshing of the micro-channel of case 1

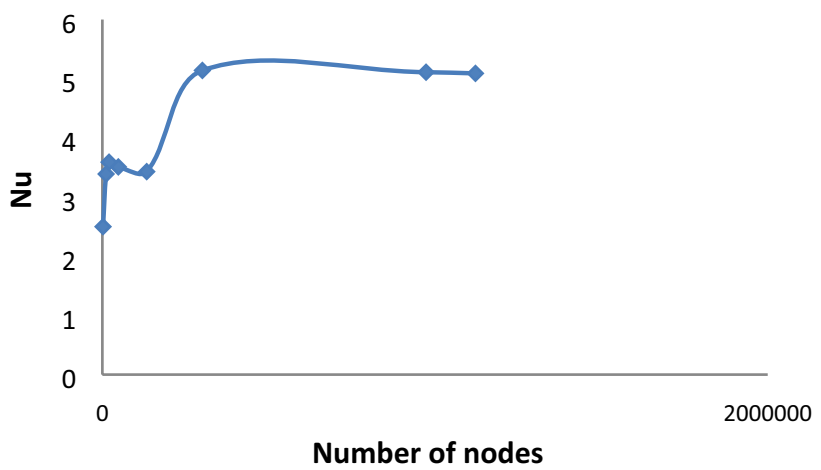

Fig. 4 Grid independence examination at $R e=200$ and heat flux of $100 \mathrm{~W} / \mathrm{cm}^{2}$

Table 3 Aspect ratio for all cases

\begin{tabular}{lllll}
\hline Aspect ratio & Case 1 & Case 2 & Case 3 & Case 4 \\
\hline Average & 1.0412 & 2.2292 & 1.8582 & 1.5221 \\
\hline
\end{tabular}

Table 4 Skewness for all cases

\begin{tabular}{lllll}
\hline Skewness & Case 1 & Case 2 & Case 3 & Case 4 \\
\hline Average & $2.018 \mathrm{e}-3$ & 0.145 & 0.1584 & 0.1185 \\
\hline
\end{tabular}

Table 5 Orthogonal quality for all cases

\begin{tabular}{lllll}
\hline Orthogonal quality & Case 1 & Case 2 & Case 3 & Case 4 \\
\hline Average & 0.9999 & 0.9111 & 0.9119 & 0.9388 \\
\hline
\end{tabular}


for energy were in the order of $10^{-6}$, and the second-order upwind scheme.

The results of the simulation are presented in this study to determine the effect of the addition of the pie-shaped ribs and parallelogram ribs in micro-channels on thermal performance. We determined the results as follows:

Figure 5 shows the evolution of temperature on the heated bottom wall for several cases. From these results, we observe that the lower temperature is on the inlet side and increases continuously towards the outlet of the micro-channel in the four cases up to a distance of

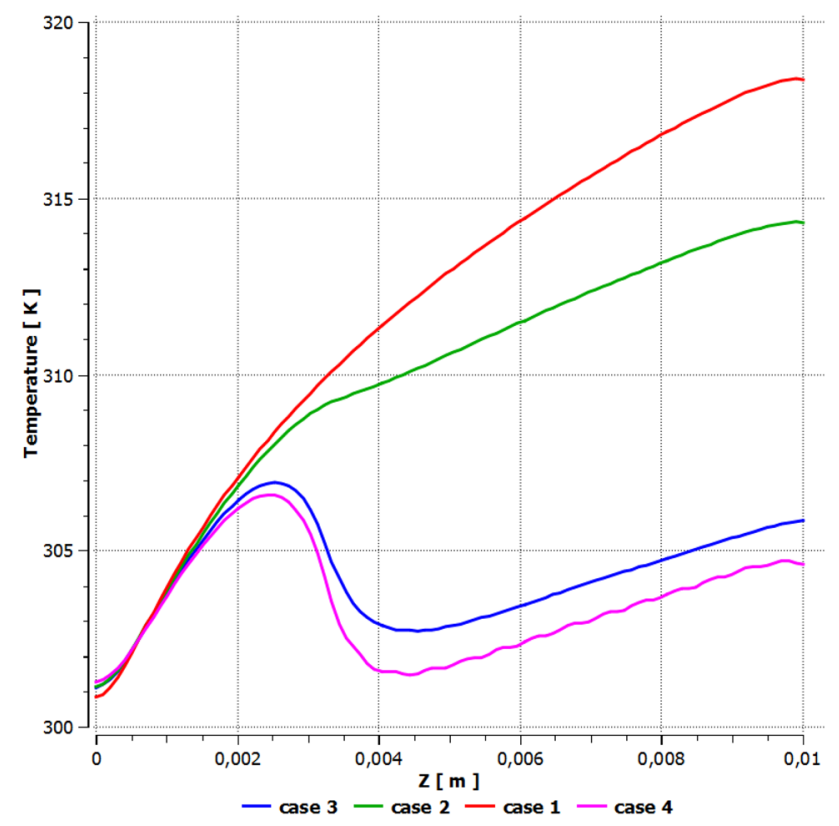

Fig. 5 Comparisons of temperature profiles on the heated bottom wall for all cases at $\mathrm{Re}=600$ and heat flux of $100 \mathrm{~W} / \mathrm{cm}^{2}$ $z=2.5 \mathrm{~mm}$ from the entrance to the micro-channel, where it decreases gradually in the third and fourth cases to a distance of approximately $z=4.5 \mathrm{~mm}$. This is due to the presence of obstacles represented by the ribs located at $z=6.67 \mathrm{~mm}$ from the outlet of the micro-channel, which contribute to lowering the temperature values, unlike the first case in which there are no ribs, where the temperature continues to rise to the exit of the micro-channel. In the second case we observe slightly lower temperature values than in the first case, which is due to the wavy shape of the sidewalls of the micro-channel located at $z=6.67 \mathrm{~mm}$ from the outlet of the micro-channel. Figure 6 shows the effect of the presence of the wavy sidewalls, the parallelogram, and pie-shaped ribs on the temperature distribution at the bottom wall of the micro-channel for all cases.

Figure 7 shows the variation in the maximum temperature on the bottom wall of the substrate with respect to the Reynolds number for the four cases. The maximum temperature decreases dramatically in all cases as the Reynolds number increases, but by varying values, because when the flow velocity increases, the ribs inside the micro-channel contribute to a greater increase in heat exchange than in the first case without the ribs. Regardless of how high the flow velocity of the nanofluid is, it remains ineffective, and the maximum temperature remains at the bottom wall of the first micro-channel, equal to $333.24 \mathrm{~K}$ at a Reynolds number of 200, unlike the fourth case (microchannel with parallelogram ribs), in which we find that the temperature is low, equal to $317.91 \mathrm{~K}$ at the same Reynolds number value.

Figure 8 shows the evolution of the maximum temperature on the bottom wall according to the Reynolds number and with the geometric parameter (Is, $W_{r}$ and $D$ ) for three cases (case 2, case 3, and case 4 ) in the second

(a)

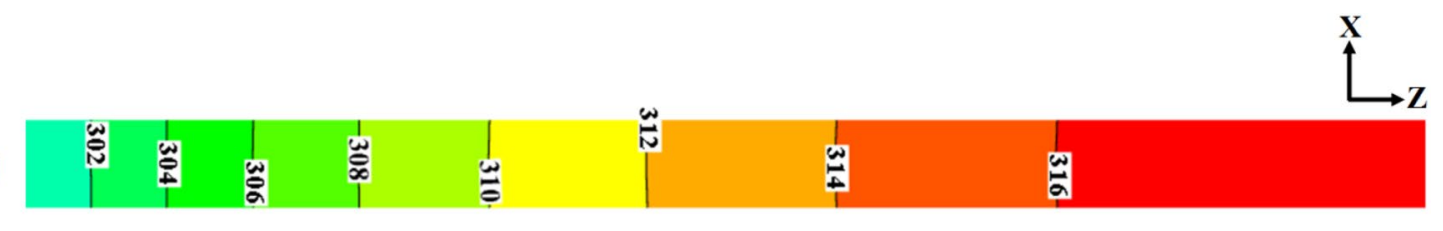

(b)

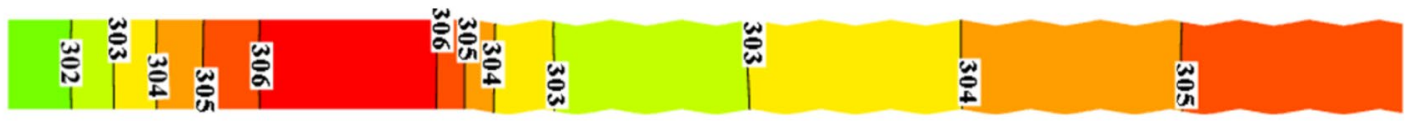

(c)

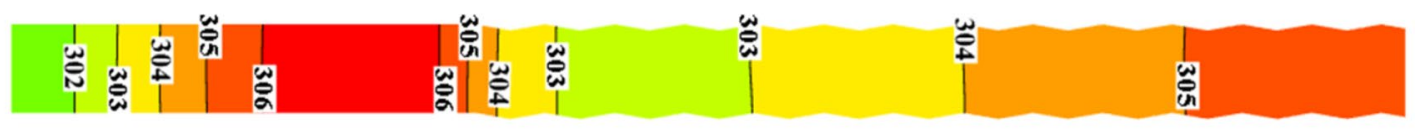

(d)

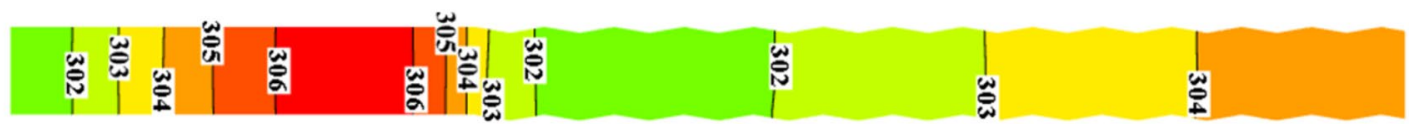

Fig. 6 Two-dimensional illustration of the temperature distribution on the bottom wall for four cases (a: case 1, b: case 2, c: case 3, and d: case 4$)$ at $\operatorname{Re}=600$ and $\varphi=0.05$; the unit is Kelvin 


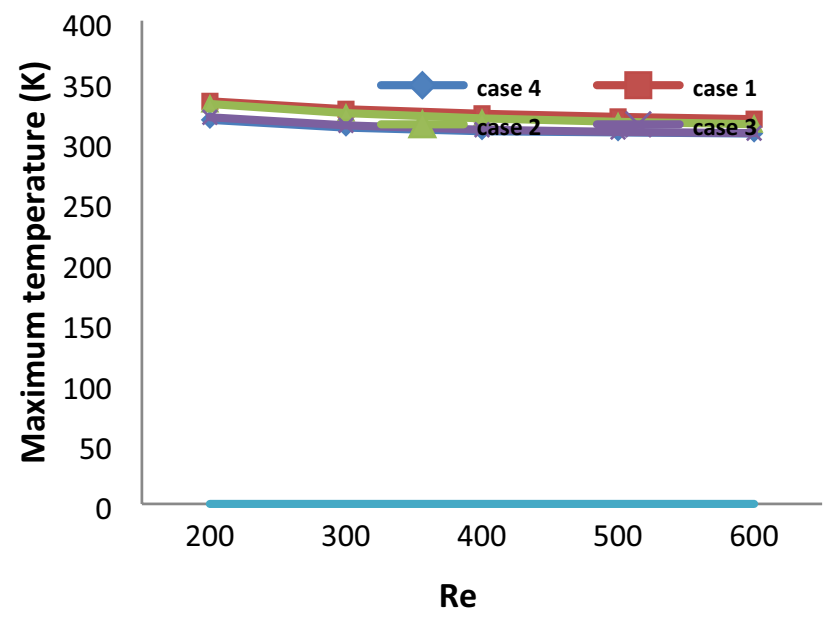

Fig. 7 The maximum temperature on the heated wall with Re ranging from 200 to 600 for four cases

case (see Fig. 8a) when the length of the wavy side walls increases. For the channel, the maximum temperature value decreases, and this is due to the increase in the contact surfaces between the nanofluid and wall of the microchannel. In Fig. 8b, the rib diameter represented in case 3 changes, so that when the diameter of the pie rib $(D)$ increases, there is a decrease in the maximum temperature of the bottom surface of the micro-channel. This occurs because an increase in diameter leads to an increase in the flow velocity at the ribs, resulting in an increase in heat transfer; the same observation is noted in Fig. $8 \mathrm{c}$ for the fourth case of a micro-channel containing parallelograms ribs. When increasing the width of the parallelogram ribs $\left(W_{r}\right)$, the hydraulic diameter of the micro-channel at the ribs decreases, which leads to an increase in the flow velocity at the regions where the ribs are located. This increase contributes to reducing the maximum temperature of the lower surface of the micro-channel. In Fig. 9, we observe the evolution of the values of the Nusselt number with the Reynolds number and with the change in the geometric parameters, i.e., the wave length of the micro-channel wall $\left(I_{s}\right)$, the diameter of the pie rib $(D)$, and the width of the parallelogram rib $\left(W_{r}\right)$. Figure 9a shows that when the contact surfaces are increased, the heat exchange increases. As a consequence, the Nusselt number increases, while the diameter of the pie ribs increases and the width of the parallelogram ribs increases (Fig. 9b and c, respectively). The Nusselt number increases due to the increase in the flow velocity at the ribs, which helps to increase the heat exchange between the micro-channel walls and the waterdiamond nanofluid.

Figure 10 shows the boundaries of the constant temperature of the plane $y=0.25 \mathrm{~mm}$ along the micro-channel for four cases at a Reynolds number (Re) equal to 600

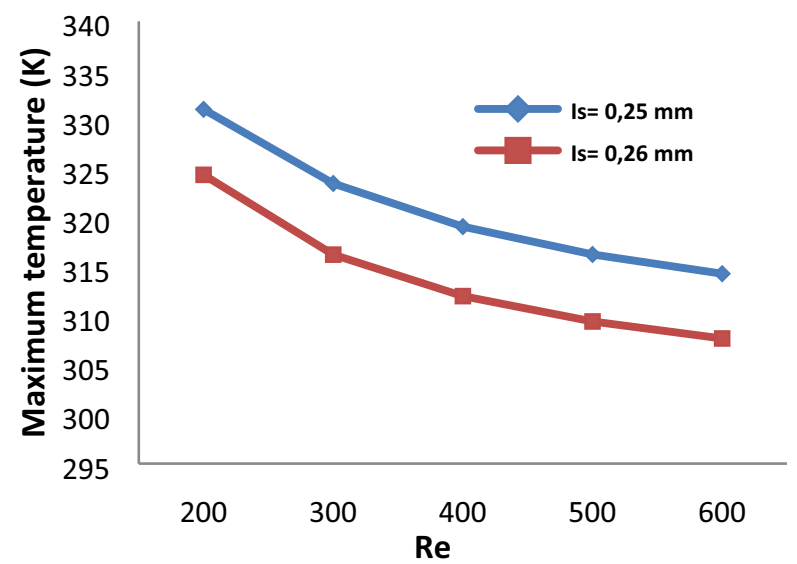

(a)

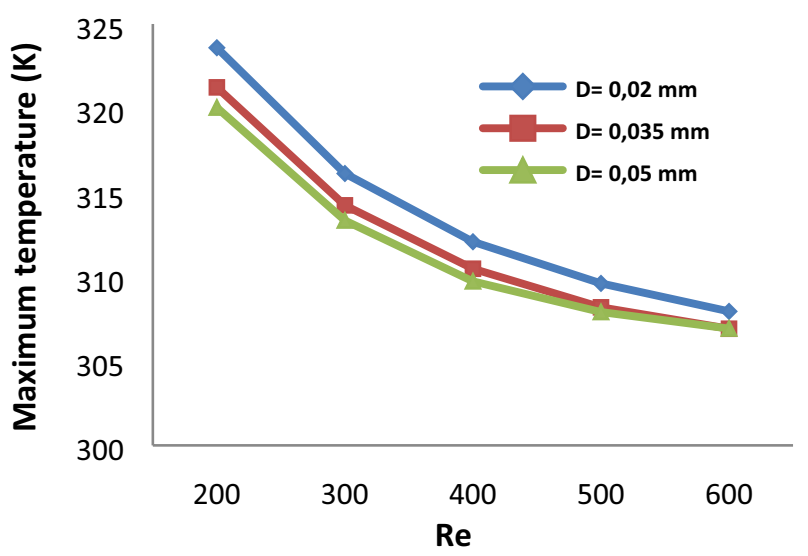

(b)

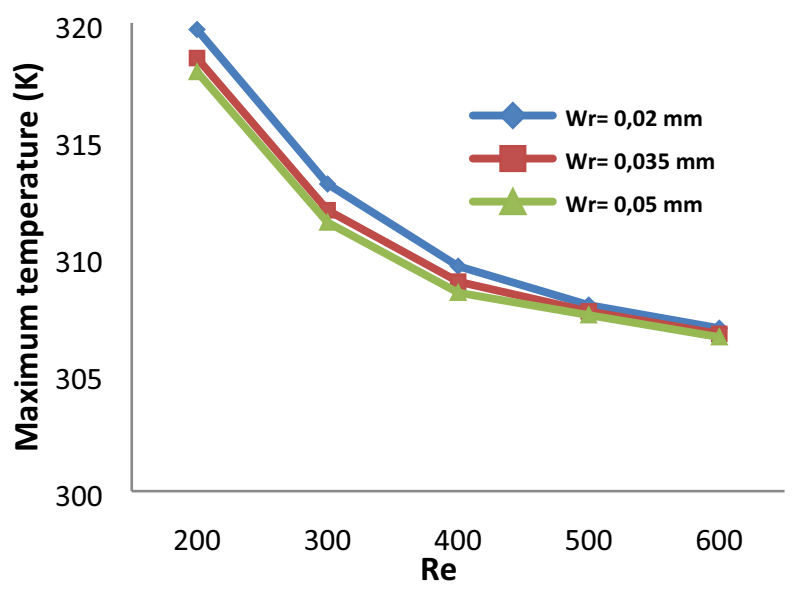

(c)

Fig. 8 Evolution of the maximum temperature as a function of Re and the geometric parameters for three cases

and the volume fraction (diamond) equal to $5 \%$. In case 1 , the temperature gradient of the diamond-water nanofluid is increased along the longitudinal z-direction from 


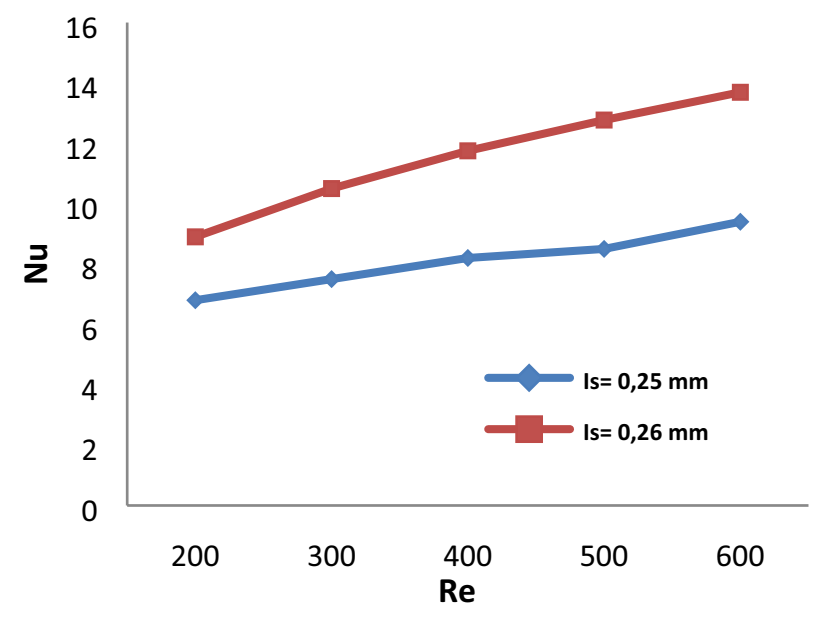

(a)

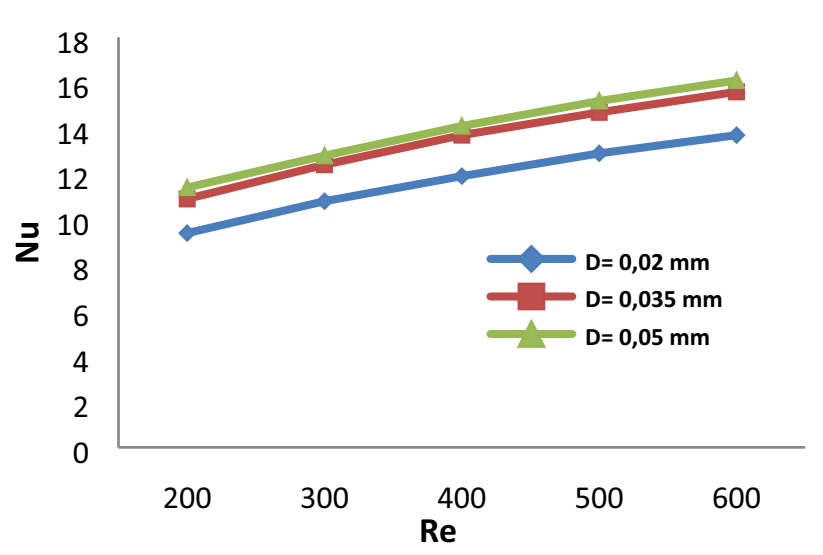

(b)

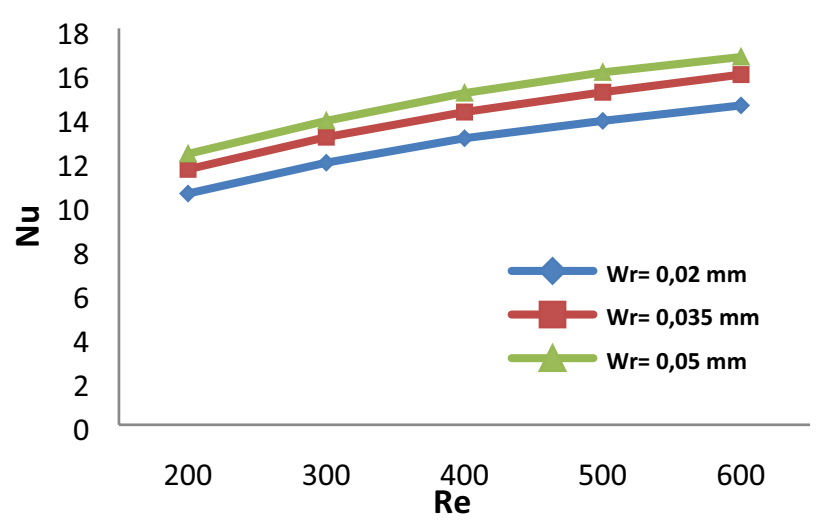

(c)

Fig. 9 Evolution of the Nusselt number as a function of the Reynolds number and geometric parameters

the micro-channel inlet to the outlet due to convection heat exchange.

By comparing the four cases, we find that the impact of the wavy walls in the second case and of the ribs in the

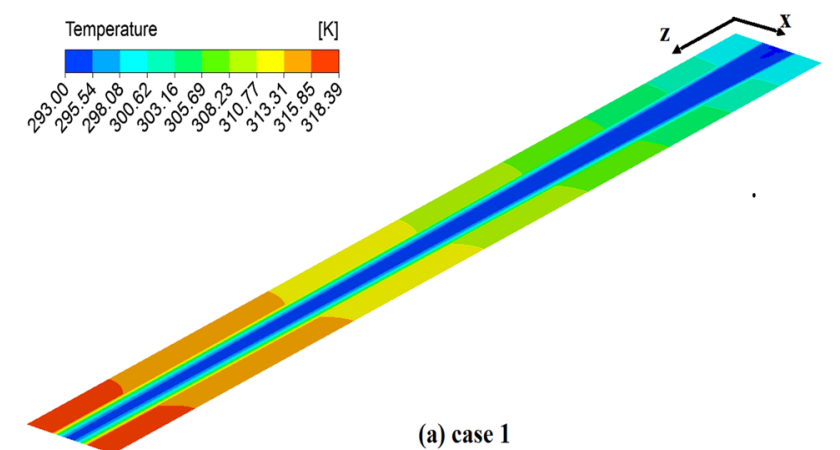

(a) case 1

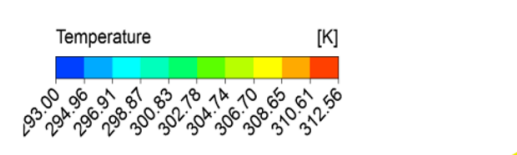

(b) case 2

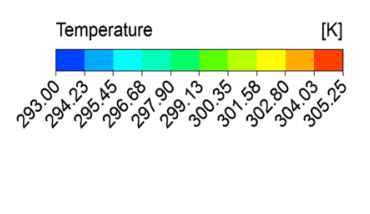

(c) case 3

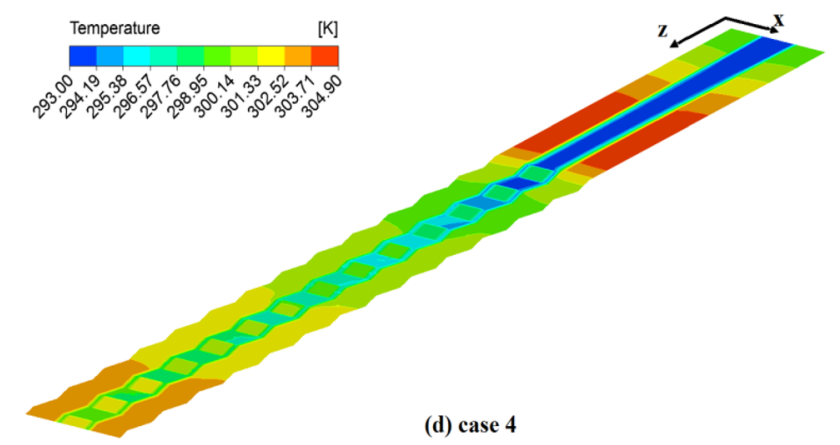

Fig. 10 Static temperature contours for the plane $y=0.25 \mathrm{~mm}$ along the length $(L)$ of the micro-channel for four cases at a Reynolds number of 600 and volume fraction equal to 0.05

\section{SN Applied Sciences}


third and fourth cases on the distribution of temperature values is markedly different, even though the third and fourth cases have the same number of ribs. This is due to the effect of the shape of the ribs inside the micro-channel, and can also be seen in the temperature values near the outlet of the micro-channel. In addition, we observe that in the first and second cases, the temperature distribution contour is somewhat similar, but there is a difference in the temperature values due to the influence of the side wavy walls located at $z=6.67 \mathrm{~mm}$ of the outlet of the channel.

Figure 11 shows the variation in the thermal resistance with the Reynolds number for four different MCHS. The results show that the micro-channel in the first case has the highest thermal resistance value, and lower resistance is found in the micro-channel of the third and fourth cases.

Figure 12 shows the average heat exchange coefficient calculated as a function of the Reynolds number (Re) in a volume concentration of 0.05 for the four cases. The average heat transfer coefficient is proportional to Re varying from 200 to 600 . Comparing the four micro-channels, the micro-channel with parallelogram ribs has the highest values, as the heat dispersants in this case (the fourth case) give a better average thermal exchange coefficient than case 3 , and case 3 is better than case 2 and case 1 . It is observed that, in all cases, the average thermal exchange coefficient increases linearly with Re. The same phenomenon is observed in Fig. 13, which shows an increase in the Nusselt number with the inlet Reynolds number. The reason is that when the flow velocity is increased, the flow rate of the liquid is increased as well, so its ability to remove heat is greater. Also, the increase in the contact surfaces by the addition of ribs in the micro-channel contributes to the increase in the thermal exchange between the walls of the micro-channel heat sinks and coolant. In our study, the results show that the parallelogram ribs in

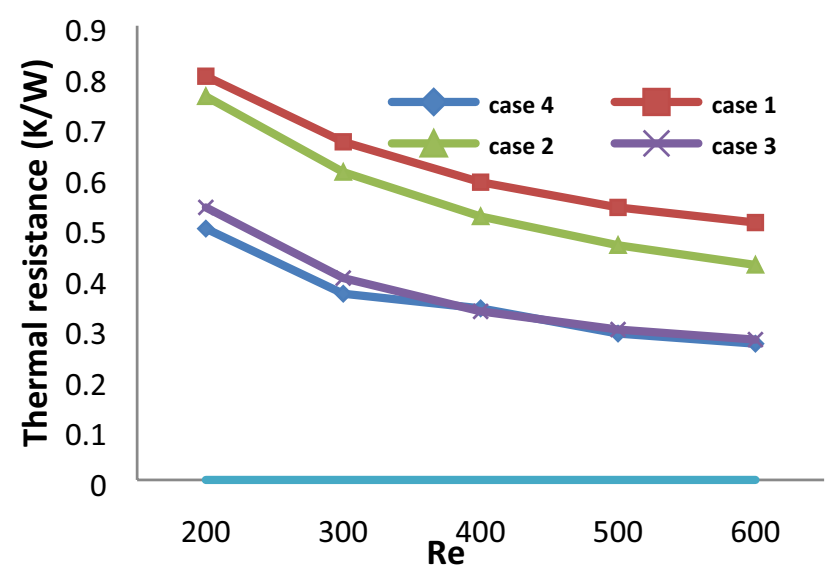

Fig. 11 Thermal resistance relative to the Reynolds number (Re) for four cases

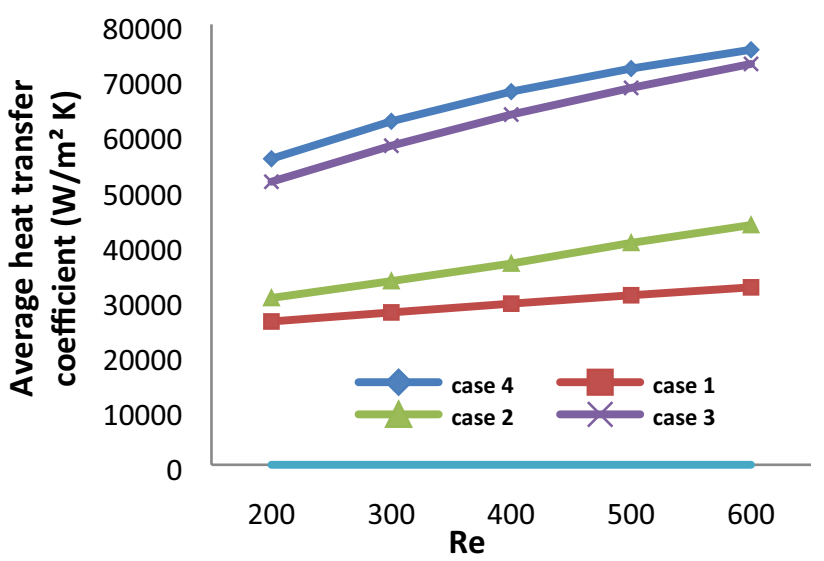

Fig.12 Average heat transfer coefficient of the micro-channels as a function of the Reynolds number (Re) for four cases

the fourth case are the most effective in improving the thermal exchange and thus decreasing the temperature of the surface heat in the bottom of the micro-channels.

Figure 14 shows the evolution of the friction factor with the Reynolds number for the four cases studied. The results show that the friction factor decreases with the increase in Re for the different micro-channels. We also note that the friction factor decreases at a smaller rate in the first and second cases than in the third and fourth cases, in which we find the friction coefficient decreases by a large percentage. It can be inferred that the addition of parallelogram and pie-shaped ribs to the micro-channel results in a greater increase in the friction factor than in the rectangular micro-channel (case 1) and the micro-channel in case 2 for all Reynolds number values. However, the friction factor in the case 4 channels is still higher than that for cases 3, 2, and 1 .

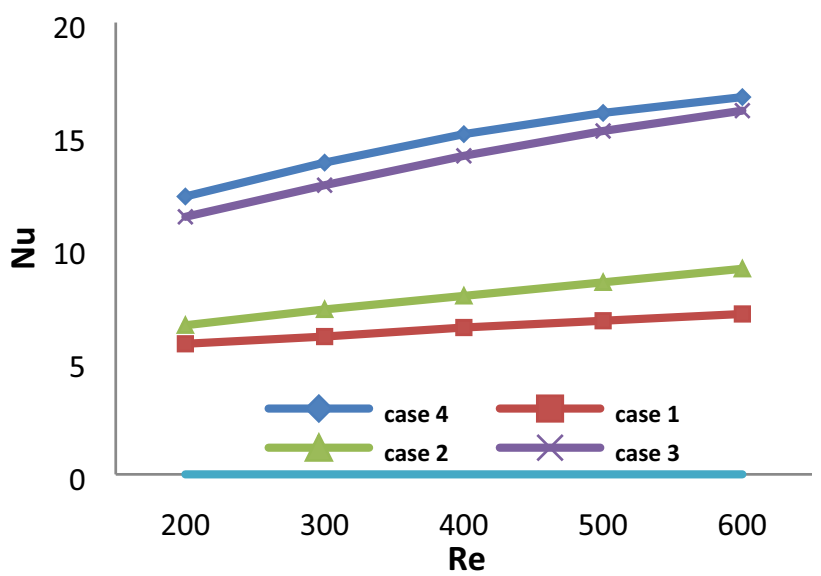

Fig. 13 Variation in Nusselt number as a function of the Reynolds number for four cases 

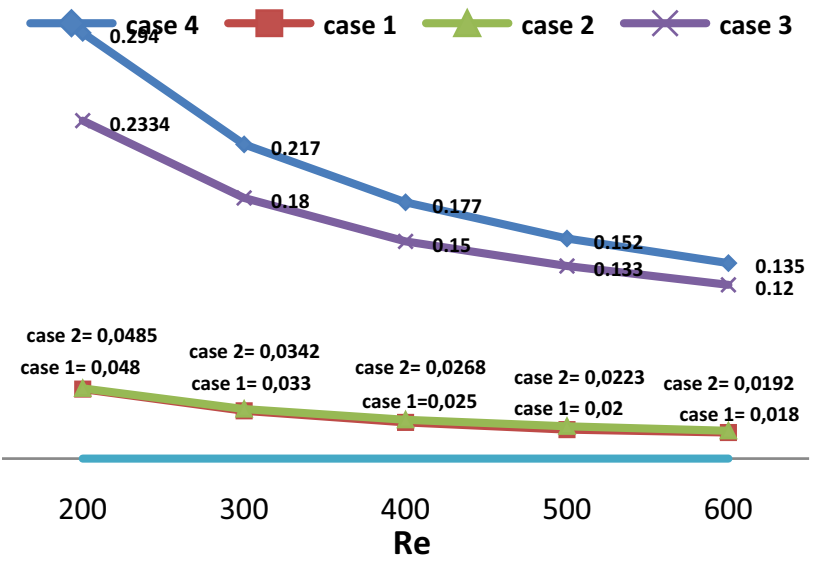

Fig. 14 Average friction factor of all cases as a function of Reynolds number for $Q=100 \mathrm{~W} / \mathrm{cm}^{2}$

\section{Conclusions}

The present research deals with the effect of added parallelogram ribs and pie-shaped ribs in micro-channels on thermal exchange and on improving the cooling of electronic components using a nanofluid (diamond- $\mathrm{H}_{2} \mathrm{O}$ ) as a coolant. The results show that the flow velocity increases and the temperature values of the heated bottom wall decrease in all cases. We also found that the lowest temperature values were obtained with the micro-channel containing the parallelogram ribs. While the thermal resistance of the micro-channel decreases in all cases, we note that the highest friction factor values of the micro-channel are observed with parallelogram ribs, and the microchannels in the first and second cases have the highest thermal resistance values. Moreover, we found that the lowest thermal resistance was obtained in the microchannel with pie-shaped and parallelogram ribs. The results also show that the maximum Nusselt number and the average coefficient of heat exchange are found in the micro-channel that contains parallelogram ribs. As a result, they are more effective in improving the cooling of highpower electronic components than the micro-channel with pie-shaped ribs. As recommendations to complete the research, we suggest the use of nanofluids with excellent physical properties as hybrid nanofluid. Additionally, the cooling efficiency can be increased by changing the shape and position of the ribs inside the micro-channel and then tested.

\section{Compliance with ethical standards}

Conflict of interest The authors declare that there are no conflicts of interest regarding the publication of this manuscript.
Open Access This article is licensed under a Creative Commons Attribution 4.0 International License, which permits use, sharing, adaptation, distribution and reproduction in any medium or format, as long as you give appropriate credit to the original author(s) and the source, provide a link to the Creative Commons licence, and indicate if changes were made. The images or other third party material in this article are included in the article's Creative Commons licence, unless indicated otherwise in a credit line to the material. If material is not included in the article's Creative Commons licence and your intended use is not permitted by statutory regulation or exceeds the permitted use, you will need to obtain permission directly from the copyright holder. To view a copy of this licence, visit http://creativecommons. org/licenses/by/4.0/.

\section{References}

1. Xia GD, Jiang J, Wang J, Zhai YL, Ma DD (2015) Effects of different geometric structures on fluid flow and heat transfer performance in microchannel heat sinks. Int J Heat Mass Transf 80:439-447

2. Zhai Y, Xia GD, Liu XF, Li YF (2014) Heat transfer in the microchannels with fan-shaped reentrant cavities and different ribs based on field synergy principle and entropy generation analysis. Int J Heat Mass Transf 68:224-233

3. Shen S, Xu JL, Zhou JJ, Chen Y (2006) Effects flow and heat transfer in microchannels with rough wall surface. Energy Convers Manag 47:1311-1325

4. Weerapun D, Somchai W (2008) Effect of thermophysical properties models on the predicting of the convective heat transfer coefficient for low concentration nanofluid. Int Commun Heat Mass Transfer 35:1320-1326

5. Promvonge $P$, Sripattanapipat $S$, Kwankaomeng S (2010) Laminar periodic flow and heat transfer in square channel with 45 inline baffles on two opposite walls. Int J Therm Sci 49(6):963-975

6. Nikkhah Z, Karimipour A, Safaei MR, Forghani-Tehrani $P$, Goodarzi M, Dahari M, Wongwises S (2015) Forced convective heat transfer of water/functionalized multi-walled carbon nanotube nanofluids in a microchannel with oscillating heat flux and slip boundary condition. Int Commun Heat Mass Transfer 68:69-77

7. Gui-Lian W, Da-Wei Y, Yan W, Di N, Xiao-Lin Z, Gui-Fu D (2015) Heat transfer and friction characteristics of the microfluidic heat sink with variously-shaped ribs for chip cooling. Sensors 15:9547-9562

8. Akbari OA, Safaei MR, Goodarzi M, Akbar NS, Zarringhalam M, Shabani GAS, Dahari M (2016) A modified two-phase mixture model of nanofluid flow and heat transfer in a 3-D curved microtube. Adv Powder Technol 27(5):2175-2185

9. Safaei MR, Gooarzi M, Akbari OA, Shadloo MS, Dahari M (2016) Performance evaluation of nanofluids in an inclined ribbed microchannel for electronic cooling applications. In: Sohel Murshed SM (ed) Electronics cooling. Intech, London

10. Ali Akbari O, Toghraie D, Karimipour A, Reza Safaei M, Goodarzi M, Alipour H, Dahari M (2016) Investigation of rib's height effect on heat transfer and flow parameters of laminar water$\mathrm{Al}_{2} \mathrm{O}_{3}$ nanofluid in a rib micro channel. Appl Math Comput 290:135-153

11. Behnampour A, Akbari OA, Safaei MR, Ghavami M, Marzban A, Shabani GAS, Zarringhalam M, Mashayekhi R (2017) Analysis of heat transfer and nanofluid fluid flow in microchannels with trapezoidal, rectangular and triangular shaped ribs. Physica $E$ Low Dimens Syst Nanostructures 91:15-31 
12. Goodarzi M, Javid S, Sajadifar A, Nojoomizadeh M, Motaharipour SH, Bach QV, Karimipour A (2019) Slip velocity and temperature jump of a non-Newtonian nanofluid, aqueous solution of carboxy-methyl cellulose/aluminum oxide nanoparticles, through a microtube. Int J Numer Meth Heat Fluid Flow 29(5):1606-1628

13. Sharad DP, Sagar CW (2018) Numerical investigation on effect of geometrical variations in microchannel heat sink. Int Res J Eng Technol (IRJET) 05(02):1519-1525

14. Jadhav SV, Pawar PM, Ronge BP (2018) Effect of pin-fin geometry on microchannel performance. J Chem Prod Process Model 14(1):1934-2659

15. Rezazadeh R, Pourmahmoud N, Asaadi S (2018) Numerical investigation and performance analyses of rectangular mini channel with different types of ribs and their arrangements. Int J Therm Sci 132:76-85

16. Bagherzadeh $S A$, Jalali E, Sarafraz MM, Ali Akbari O, Karimipour A, Goodarzi M, Bach QV (2019) Effects of magnetic field on micro cross jet injection of dispersed nanoparticles in a microchannel. Int J Numer Meth Heat Fluid Flow 30(5):2683-2704

17. Goodarzi M, Tlili I, Tian Z, Safaei MR (2019) Efficiency assessment of using graphene nanoplatelets-silver/water nanofluids in microchannel heat sinks with different cross sections for electronics cooling. Int J Numer Meth Heat Fluid Flow 30(1):347-372

18. Mehdi B, Mohammad J, Marjan G (2019) Efficacy of a hybrid nanofluid in a new microchannel heat sink equipped with both secondary channels and ribs. J Mol Liq 273:88-98

19. Gheynani AR, Akbari OA, Zarringhalam M, Shabani GAS, Alnaqi AA, Goodarzi M, Toghraie D (2019) Investigating the effect of nanoparticles diameter on turbulent flow and heat transfer properties of non-Newtonian carboxymethyl cellulose/ $\mathrm{CuO}$ fluid in a microtube. Int $\mathrm{J}$ Numer Meth Heat Fluid Flow 29(5):1699-1723

20. Wang G, Chen T, Tian M, Ding G (2020) Fluid and heat transfer characteristics of microchannel heat sink with truncated rib on sidewall. Int J Heat Mass Transf 148:119142

21. Massimo C (2011) Empirical correlating equations for predicting the effective thermal conductivity and dynamic viscosity of nanofluids. Energy Convers Manag 52(1):789-793
22. Fohanno S, Polidori G, Popa C (2012) Nanofluides et transfert de chaleur par convection naturelle. Université de reims champagne-Ardenne, France

23. Khanafer K, Vafai K, Lightstone M (2003) Buoyancy-driven heat transfer enhancement in a two dimensional enclosure utilizing nanofluids. Int J Heat Mass Transfer 46:3639-3653

24. Gunnasegaran P, Shuaib NH, Mohammed HA, Abdul Jalal MF, Sandhita E (2012) Heat transfer enhancement in microchannel heat sink using nanofluids. In: Hector Juarez L (ed) Fluid dynamics computational modeling and applications. InTech, London, pp 287-326

25. Hung TC, Yan WM, Wang XD, Chang CY (2012) Heat transfer enhancement in microchannel heat sinks using nanofluids. Int J Heat Mass Transf 55:2559-2570

26. Moraveji MK, Ardehali RM, ljam A (2013) CFD investigation of nanofluid effects (cooling performance and pressure drop) in mini-channel heat sink. Int Commun Heat Mass Transfer 40:58-66

27. Gongnan X, Shian L, Bengt S, Weihong Z, Haibin L (2014) A numerical study of the thermal performance of microchannel heat sinks with multiple length bifurcation in laminar liquid flow. Numer Heat Transfer Part A 65:107-126

28. Chai L, Wang L, Bai X (2019) Thermohydraulic performance of microchannel heat sinks with triangular ribs on sidewalls-part 2: average fluid flow and heat transfer characteristics. Int J Heat Mass Transf 128:634-648

29. Chai L, Xia G, Wang L, Zhou M, Cui Z (2013) Heat transfer enhancement in microchannel heat sinks with periodic expansion-constriction cross-sections. Int J Heat Mass Transf $62: 741-751$

Publisher's Note Springer Nature remains neutral with regard to jurisdictional claims in published maps and institutional affiliations. 